\title{
Exploration and Practice of Animation Major Reform in Higher Vocational Colleges under the Mode of Integration of Production and Education
}

\author{
ZHANG Wei-guo, LIU Lai-quan, CAI Zan-hong \\ Hainan College of Software Technology \\ 913252072@qq.com
}

\begin{abstract}
Key words: integration of production and education, animation major, reform
\end{abstract}
\begin{abstract}
School-enterprise cooperation is the basis of the reform and development of animation major in high vocational colleges, and production and education integration is an important guarantee to improve the quality of education. Animation major in high vocational colleges should hold the great standard of school-enterprise cooperation to conduct cooperation at a higher level with enterprises and integrate "production"with"education"deeply, reform the current professional curriculum system and personnel training methods and actively carry out project teaching, in order to establish studio and the new modern apprenticeship system which are conducive to high-quality animation personnel training.
\end{abstract}

\section{Introduction}

The State Council issued the "Opinions on promoting cultural creativity and design services and related industries integration "in 2014, which clearly put forward that we should excavate outstanding cultural resources deeply, promote the animation industry optimization and upgrading, and build national brand. In 2016, the General Office of the State Council issued the "The Outline of the Action Plan for Improving Scientific Literacy for All (2016-2020)" that pointed that we should vigorously carry out science fiction, animation, video, games and other popular science creation, strengthen international exchanges and cooperation of the popular science creation.At present, the animation and related professional have been flourishing in vocational colleges, industrial parks, animation bases also spring up in the major cities, and the animation has become the television channel.A variety of outstanding animation works continue to emerge, the demand for animation talent is also increasing and projects on animation talent training also appear in an endless stream. And the teaching reform models related to animation professional construction are emerging, including "project-based teaching", "order-style training", "technology combination", "school-enterprise cooperation", "studio" and "apprenticeship",making the animation transform from a starving "baby" into a vibrant "youth".Animation major development in vocational colleges will usher a deep start due to the national policy support and urgent publicity and promotion of the profound Chinese culture.However, there are some factors that are not conducive to its deep development according to the current situation : the traditional curriculum system, the superficial school-enterprise cooperation and the slogan-style regional economic construction.These can directly lead to the low animation talent quality and the few original animation works, resulting in students can not be employed after graduation and rare independent undertaking.

\section{Research on Vocational Education under the Mode of Deep Integration of Production and Education}

The Third Plenary Session of the eighteen stressed that "we should speed up the construction of modern vocational education system, deepen integration of production and education, school-enterprise cooperation and train high-quality skilled personnel."Xi Jinping, general secretary pointed out that we should firmly grasp the service development, promote the employment, deepen the reform of institutional mechanisms, innovate vocational education models at all levels, adhere to 
integration of production and education, school-enterprise cooperation, technology combination, unity of knowing and doing, guide actively support of vocational education in industry and enterprises and strive to build vocational education system with Chinese characteristics.Premier $\mathrm{Li}$ Keqiang also pointed out in the State Council executive meeting on February 26, 2014 to"fully mobilize the social forces, attract more resources to the vocational education, accelerate the modern vocational technical education with integration of production and education adapting to development of technological progress and the reform of production methods and social public services."The deep integration of production and education is the basis of modern vocational education development and the guarantee to enhance the quality of modern vocational education.Enterprises need education and education needs enterprises. Only when schools and enterprises are united can we develop our vocational education faster and better. The deep integration of production and education models are:schools rely on enterprises to apply for a new professional industry, schools rely on the professions to establish school-run enterprises, schools employ business experts into the classroom,schools and enterprises establish a common studio, schools introduce the enterprise entity projects, enterprises help train teachers for schools. Our animation professional has established cooperative relationships with a number of enterprises since 2009, and set up the school-run enterprises in 2013.In order to ensure the deep integration of production and education, enterprises and professionals jointly develop the modular curriculum system, establish the cooperation through the project, set up the diversified studio taking enterprise experts as the core and form three-level"master, tutor and teacher" modern new apprenticeship.

1."Modularization" Curriculum System under the Deep Integration of Production and Education. At present, animation professional inmost higher vocational colleges and universities has insufficient market research and "following the trend" of professional reporting,with low teachers abilities and without any business as the basis in professional construction process, and the professional curriculum can not set based on the needs of enterprise positions. To successfully run a professional,we must have a mature teaching team, which should include the backbone enterprise personnel in addition to professional teachers, for business people can really understand the business needs of talent standards. Our animation professional has successfully implemented a set of mature curriculum--modular curriculum system led by the project in cooperation with enterprises for many years and through long-term integration of production and education.The course system is completed entirely under the guidance of professional personnel and the backbone staff in enterprises."Education" in the course system is to divide the 3D animation into three modules model and chart-let, setting and animation, 3D Layout and later stage.Model and chart-let involve MAYA model production, MAYA material set, MAYA chart-let, MAYA light and rendering set; setting and animation model involve anatomy, bone settings, bone binding and the role animation; 3D Layout and later stage involve animation script creation, animation sub-lens production, the location and placement of the camera, 3D storyboard production, post-effects, editing and synthesis."Production"in the course system is to join the "actual combat" link after completing the course contents.Students learn the modular knowledge in the short time mainly through the simulation project training, after learning the module,they can participate in the actual projects. Through the actual projects,students can test their inadequacies and then come back to learn, and ultimately have the comprehensive understanding of the entire animation process.

2."Project - based" Teaching under the Deep Integration of Production and Teaching. "Education"takes the production as the goal, "production" is the prerequisite of education. The essence of vocational education is "production", to cultivate high-quality talents and create new products serving the regional economic development.The basis of integration of production and education is "production", to take the real production as the premise and carry out professional practice teaching in such a foundation and atmosphere,so students can learn real skills and teachers can teach well."Project-based" teaching can greatly develop the potentials of students,and stimulate students enthusiasm to create new products.In the long-term practice teaching, our college has introduced the real business projects such as CCTV animation, Hainan characteristic culture animation through the mode of school-enterprise cooperation and encouraged students to participate 
in various animation projects, taking the project as the main line and leading students professional learning.The "project-based" teaching of the integration of production and education is divided into the following links:firstly,teachers can divide the completed one or more commercial animation projects into several sub-projects and take to the entire teaching process, and students continue to master the knowledge essentials through classroom experiments in the teaching process; secondly, arrange a course training after students completing the sub-projects.Students can independently complete a complete animation project through 1 to 2 weeks of training courses; thirdly,students will be arranged for a real business project after learning the knowledge of all the modules,during this link, students can gradually understand and master enterprise standards and culture, which lays a good foundation for students direct employment.

3."Studio" Teaching Mode under the Deep Integration of Production and Teaching. Studio teaching mode is to train students innovative, artistic, practical and application abilities, to take the studio as the carrier and integrate course teaching and production practice.The "studio" teaching mode under the deep integration of production and teaching is to play the function of "production" and "education" in the studio,take the industry masters as the commanders and in charge of the project introduction or project creation, and standards development, so students will be arranged into a specific project production team to give full play the innovative thinking and teamwork skills according to the requirements of the project standards and the characteristics of the students.Our studio established by animation professional has formed a wide range of artistic space under the model of the deep integration of production and education : the powerful animation script, vivid painting works, graceful role modeling and smooth action design.

4."New Modern Apprenticeship" under the Deep Integration of Production and Education. Apprenticeship can be divided into traditional apprenticeship, modern apprenticeship and cognitive apprenticeship according to its development.Traditional apprenticeship is the personnel training mode that a master leads a few pupils to work in workshop, which is the embryonic form of vocational education development, but not conducive to the comprehensive development of talents and the healthy development of modern vocational education.Modern apprenticeship is a teaching model in which both enterprises and schools jointly cultivate talents,students learn while working and reflect the thinking of"learning by doing and working by learning".Cognitive apprenticeship is to combine the education mode with the core technology of the enterprise and cultivate students' cognitive skills. "New modern apprenticeship" developed and explored by our school for a long time under the deep integration of production and education is a "one to many" training network to combine the industry experts, professional teachers, school-run enterprise backbone and students.Industry experts are responsible for industry standards and core technology training of professional teachers, professional teachers are responsible for industry standards and core technology training of the backbone of the school-run enterprises, and finally realize the industry standards and core technology training objectives of backbone enterprises for students. This new modern apprenticeship has fully exerted the advantages of both corporate culture and school education, and realized the prefect combination of the core technology of the enterprises with the educational function of the school, which are conducive to the sustainable development of the students.In this new modern apprenticeship, our school appears many great animation professionals successively, school-run enterprises continue to absorb the fresh graduates excellent strength,teachers' knowledge system is continuously enriched and strengthened,the creative ability of talents at all levels has been greatly improved and able to stand out in various competitions.

\section{Conclusion}

As a new growth point of China's economic development, animation industry has received more and more attention from the party and the government. The integration of production and teaching and school-enterprise cooperation is the only way for the animation professional development and a new thinking of the animation reform in higher vocational colleges.Animation major reform in higher vocational colleges should strengthen the cooperation between schools and enterprises, take the road of integration of production and education, establish a new modern apprenticeship 
constantly from the curriculum system,faculty structure and the commercial project creation, in order to further explore a personnel cultivation mode suitable for animation professional development.

This paper is one of the periodic results in the light of Hainan province higher education teaching reform project "school enterprise integration and cooperation of study and practice of talents cultivation mode of animation design and production as an example" (Hnjg2016-75)

\section{References:}

[1]http://www.gov.cn/zhengce/content/2014-03/14/content_8713.htm

[2]Jiang Hongyu.A Research on Animation Design and Production Personnel Training under the mode of Studio System.Education Forum[J].2012(06)

[3]http://edu.gmw.cn/newspaper/2014-08/16/content_100096398.htm

[4] Qin Bin.The deep integration of production and education--an important direction for the development of modern vocational education[N].Guangxi Daily.2014.8

[5] Ye Yuwen. Teaching Reform Strategy of Animation Specialty from the Perspective of Animation Industry Development [J]. Yalujiang Literature Monthly, 2015, (11) :132.

[6] He Hui, Huang Baiqing. A Rustic Opinion on Basic Theory Education in China [J]. Art Research, 2012, (4) 77-80.

[7] Wang Ruyi, Mo Xinping. Application and Exploration of "Celebrity Studio" Talent Cultivation Mode in Animation Design and Production Specialty Education [J]. China Adult Education 2015, (9): 140-142. 